\title{
Air Pollution Related to Traffic and Chronic Respiratory Diseases (Asthma and COPD) in Africa
}

\author{
Fatou K. Sylla ${ }^{*}$, Adama Faye ${ }^{1}$, Mamadou Fall ${ }^{2}$, Anta TAL-DIA ${ }^{1}$ \\ ${ }^{1}$ Institute of Health and Development-Public Health and Preventive Medecine, Cheikh Anta Diop University (UCAD), \\ Dakar, Senegal \\ ${ }^{2}$ Laboratory of Toxicology and Hydrology, Cheikh Anta Diop University (UCAD), Dakar, Senegal \\ Email: ^f.sylla@outlook.fr, adamafaye94@gmail.com,madoufal@gmail.com, adia@ised.sn
}

How to cite this paper: Sylla, F.K., Faye, A. Fall, M. and TAL-DIA, Anta (2017) Air Pollution Related to Traffic and Chronic Respiratory Diseases (Asthma and COPD) in Africa. Health, 9, 1378-1389.

https://doi.org/10.4236/health.2017.910101

Received: August 15, 2017

Accepted: September 22, 2017

Published: September 25, 2017

Copyright $\odot 2017$ by authors and Scientific Research Publishing Inc. This work is licensed under the Creative Commons Attribution International License (CC BY 4.0).

http://creativecommons.org/licenses/by/4.0/

\begin{abstract}
Introduction: Chronic respiratory diseases (CRD) are obvious effects of air pollution and the third reason of death in developing countries. In Africa, air pollution from road traffic is one of the main causes of poor air quality. We set out to systematically review existing published researches on traffic related to air pollution and CRD, particularly asthma and Chronic Obstructive Pulmonary Disease (COPD) in Africa. Methods: A literature search of PubMed, Scholar and LISSA databases, published journals, reference articles, published up to 31 December 2016, has been done by using a research strategy procedure. Texts were reviewed for inclusion. Studies were included if they met the following criteria: 1) the relationship between asthma or COPD with ambient air pollution related to road traffic was studied and 2) the population included people from Africa or lived in Africa. Articles written in English and French were included. Results: Fifty-five articles were selected in this review, of which twenty-seven were on air pollution and CRD in Africa. The proximity of the residence or workplace to the traffic is associated with an increased risk of asthma with a dose-response relationship. The estimated prevalence of COPD varies between $2.7 \%$ and $38.5 \%$. Conclusion: There is little research on traffic related to air pollution and CRD in Africa. Strategies to reduce traffic related to air pollution in African cities have been proposed in order to have a healthier ambient air.
\end{abstract}

\section{Keywords}

Air Pollution, Traffic, Africa, Asthma, COPD

\section{Introduction}

Air pollution is an important environmental risk factor with global public health 
implications. The World Health Organization (WHO) estimates that outdoor air pollution could cause 3.7 million of premature deaths worldwide in 2012 [1]. In Africa, premature deaths caused by indoor and outdoor air pollution increased by $36 \%$ between 1990 and 2013 . The number of annual deaths due to air pollution increased from 180,000 in 1990 to 250,000 in 2013 [2]. On average, an adult breathes $10-15 \mathrm{~m}^{3}$ of air per day. Inhalation represents the fundamental mechanism of exposure to airborne pollutants in humans [3]. Therefore, the respiratory system becomes a primary target of the harmful effects of major air pollutants for health, including particle matter $(\mathrm{PM})$, ozone $\left(\mathrm{O}_{3}\right)$ and nitrogen dioxide $\left(\mathrm{NO}_{2}\right)$ [4]. Air pollution is associated with the occurrence and exacerbation of chronic respiratory diseases (CRD), particularly asthma and Chronic Obstructive Pulmonary Disease (COPD) [5]. The world's population is facing a well-known and recognized global epidemic of chronic respiratory diseases, with the highest burden expected in sub-Saharan Africa [6].

Chronic respiratory diseases are responsible for 4.2 million deaths a year worldwide, nearly $80 \%$ of which occur in low- or middle-income countries [1]. The burden of chronic respiratory diseases such as asthma and COPD is unknown in Africa [7] but should be high due to environmental conditions such as air pollution. Urbanization rates in Africa are among the highest in the world, with more than half of the population expected to reside in urban areas by 2035 [8]. Traffic related to air pollution is a major part of pollution sources in big African cities. While the use of biomass fuel for domestic cooking is the main source of pollution in most African rural areas [9]. The United Nations (UN) estimates that roads account for up to $90 \%$ of urban air pollution in developing countries [10]. The United Nations Environment Programme (UNEP) also estimated that more than 600 million people in urban areas around the world, the majority of them in developing countries, particularly in Africa, were exposed to dangerous levels of air pollutants generated by traffic [11].

Indeed, the road traffic has the potential to significantly increase pollutant emissions and degrades air quality, especially near very busy main roads with car drivers. These emissions contribute to the risk of morbidity and mortality for drivers and those working or living nearby, as testified by epidemiological studies, evaluations of proposed standards for car emissions and environmental impact studies for specific road projects [12] [13].

In Africa, few studies have been carried out on traffic related to air pollution and chronic respiratory diseases compared to developed countries [7] [14]. These studies have been done in different parts of Africa and have estimated the prevalence of chronic respiratory diseases such as asthma and COPD. Traffic related to air pollution is a major environmental health issue that affects many developing countries. Residents of cities with highly polluted air suffer more from heart disease, respiratory problems than those in cities with cleaner air [15].

Given the significant increase in respiratory diseases in Africa, it is important to know the effects of air pollution related to traffic on the respiratory morbidity of African populations by the different studies that have been done in Africa. In 
most African countries, real measures against air pollution from road traffic are not implemented or applied. Realistic solutions to limit outdoor air pollution in Africa, particularly from cars have been proposed without compromising the economic policies essential to the development of the countries of the South.

The aim of this review is to present the state of knowledge in Africa on the impact of external air pollution, particularly related to traffic, on chronic respiratory diseases and to propose strategies to fight this pollution.

\section{Methodology}

\subsection{Data Sources}

The PubMed, Scholar and LISSA databases were used to identify studies published up to 31 December 2016. The keywords included in the research were air pollution, traffic and Africa, as well as Chronic Obstructive Pulmonary Disease (COPD), asthma and respiratory morbidity.

\subsection{Study Selection}

We also looked for the recent reports and reference articles related to our subject of study. Thus, the relevant studies or articles written in English and French that were made in Africa were included in the review.

\subsection{Data Extraction and Synthesis}

The extraction was done by selecting the relevant articles by examining the titles, summaries and reference lists (Figure 1).

Studies on chronic respiratory diseases resulting from air pollution related to traffic in each part of Africa have been synthesized under the categories: air

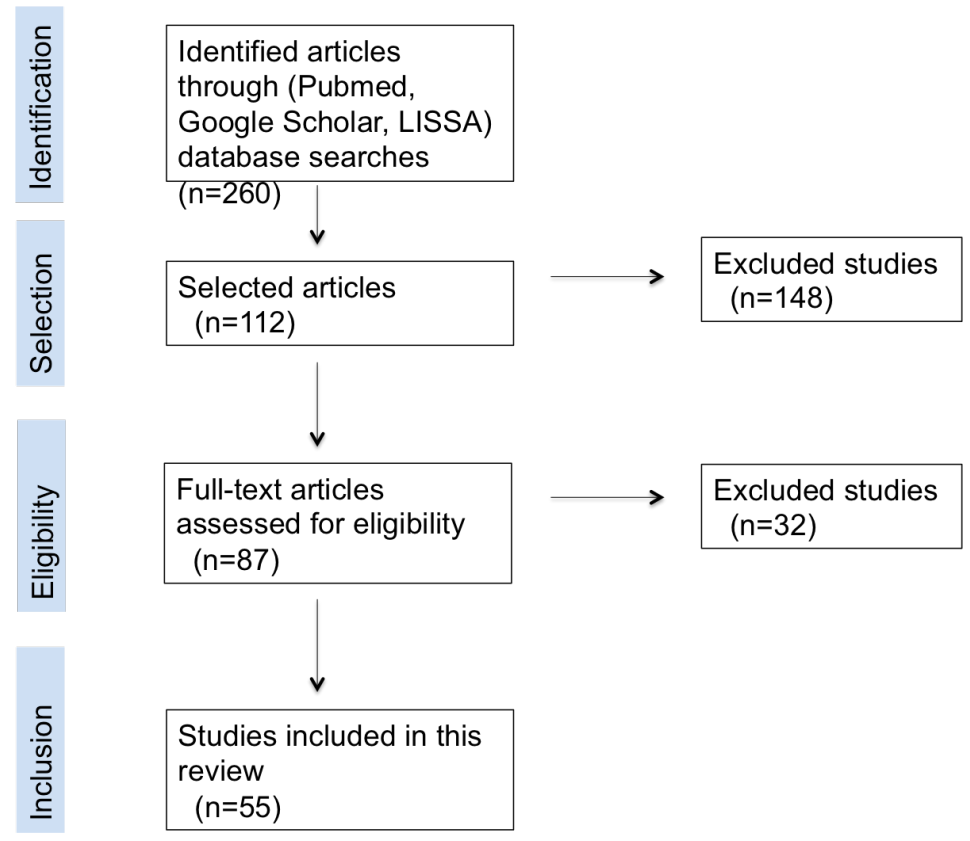

Figure 1. Selection procedure of articles included in this review. 
pollution related to traffic, epidemiology outdoor air pollution and chronic respiratory diseases, and strategies to reduce air pollution as well.

\section{Results}

\subsection{Air Pollution from Traffic: Case of Africa}

Road traffic has strongly increased in Africa and around the world over the past 20 years [16]. In several regions of Africa, car emissions have become the main sources of air pollutants, including carbon monoxide (CO), carbon dioxide $\left(\mathrm{CO}_{2}\right)$, volatile organic compounds (VOCs), and hydrocarbons $\mathrm{CHs}$ ), nitrogen oxides $\left(\mathrm{NO}_{\mathrm{x}}\right)$, and particles matter (PM) [14] [17]. African cities, as most cities in developing countries, are facing serious problems of particulate emissions from traffic [18] [19] [20]. Economic growth in African cities coupled with a lack of transportation and efficient territory management is resulting in an increase of the number of personal cars and traffic jam. The increasing severity and duration of traffic congestion significantly increase pollutant emissions and then deteriorate the air quality, especially near main roads. This is why hot spots of air pollution can be remarked near high traffic roads. Urban growth that accompanies economic growth is also continuing in a fast way in developing countries, particularly in sub-Saharan Africa [8]. This is due to the fact that rural populations continue to migrate more and more to cities looking for jobs and hoping better living conditions. This rampant urbanization will then intensify the emission of car pollutants and exacerbate the serious problems of air quality in the cities of Sub-Saharan Africa, and its effects on health as well. High concentrations of pollutants can be seen near high-traffic roads and these are gradually decreasing with distance [21]. Lamsal et al., 2013 [22] found that urban $\mathrm{NO}_{2}$ pollution is a dose-response function of the population size: the concentration of $\mathrm{NO}_{2}$ increases proportionally in relation with the size of the population in an exponential way.

The reasons for this increase in car pollutants, in particular $\mathrm{NO}_{2}$, are the import of old cars, poor vehicle maintenance, and poor infrastructures unable to support the rapid increase in the number of vehicles. Traffic emissions may harm the health of residents in sub-Saharan Africa in particular, those who walk along high-traffic roads, public transport users or those who drive cars. Studies have shown that traffic related to air pollution is becoming an increasing concern and a major public health problem [23] [24] [25] [26]. Particles matter (PM) generated by fuel combustion (for example cars with an engine) are associated with a wide range of health effects, including more than 800,000 deaths in cities around the world [21] [27]. These emissions contribute to the risk of morbidity and mortality for drivers and people living near the roads, as shown by different studies [12] [13].

\subsection{Epidemiology of Outdoor Air Pollution and Chronic Respiratory Diseases in Africa}

The harmful effects of high levels outdoor air pollution in patients with chronic 
cardiopulmonary disease have been well documented, leading to an increase of morbidity, as evidenced by the important number of people admitted in hospitals and by the mortality [28] [29] [30]. Unlike developing countries, several studies on the effects of air pollution on health have been carried out in developed countries. In Africa, few studies have been done on air pollution related to traffic on health. In the early 2000s, the Norman team [31] showed that outdoor air pollution was responsible for $3.7 \%$ of the national mortality in cardio-respiratory diseases in South Africa. Then, further studies were carried out in South Africa and demonstrated the link between air pollution and respiratory diseases.

\subsubsection{Epidemiology of Air Pollution Related to Traffic and Asthma in Africa}

In Durban, one of the most polluted cities in South Africa, it was shown that children in schools in southern Durban had a higher prevalence of asthma than children from schools in northern Durban (12.2\% vs. 9.6\%) due to the higher concentration of $\mathrm{SO}_{2}$ [32] (Table 1). Shirinde et al., 2015 [33] also showed that children living in Tembisa, the second South African region, which has been declared to be a priority zone for the fight with air pollution, had an increasing risk of wheezing (one of the symptoms of asthma) due both to sources of indoor and outdoor air pollution. Most of car pollution has been studied with children living close to roads that are frequented by trucks all days of the week. These children had a higher risk of never having wheeze (OR 1.32 95\% CI: 1.01 - 1.73), a common wheeze (OR $1.6195 \%$ CI: 1.15 - 2.24) and a severe current wheeze (OR 2.22 95\% CI: 1.28 - 3.77) (Table 1).

In Ethiopia, the proximity of residences and the risk of asthma have been studied. The Venn et al., 2005 [34] found that individuals living in less than $150 \mathrm{~m}$

Table 1. Studies in Africa on air pollution related to traffic and the risk of developing asthma following the proximity with high way traffic.

\begin{tabular}{|c|c|c|c|c|c|}
\hline \multirow[t]{2}{*}{ Population } & \multirow{2}{*}{$\begin{array}{c}\text { Number } \\
\text { of } \\
\text { people }\end{array}$} & \multicolumn{3}{|c|}{$\begin{array}{c}\text { Asthma: OR }[95 \% \mathrm{CI}] \text { based } \\
\text { on proximity to road }\end{array}$} & \multirow[t]{2}{*}{ References } \\
\hline & & No-exposed & Exposed & $\mathrm{p}$ & \\
\hline $\begin{array}{l}\text { South Africa } \\
\text { Children }\end{array}$ & 423 & 1 & $1.12[1.01-1.24]$ & 0.04 & $\begin{array}{c}\text { Naidoo et al., } 2013 \\
\text { [32]. }\end{array}$ \\
\hline $\begin{array}{l}\text { South Africa } \\
\text { Children }\end{array}$ & 3764 & 1 & $1.60[1.24-2.02]$ & 0.000 & $\begin{array}{c}\text { Shirinde et al., } 2015 \\
\text { [33]. }\end{array}$ \\
\hline $\begin{array}{l}\text { Ethiopia } \\
\text { Adults } \\
\text { Children }\end{array}$ & 3592 & 1 & $1.17[1.01-1.36]$ & 0.03 & $\begin{array}{c}\text { Venn et al., } 2005 \\
\text { [34]. }\end{array}$ \\
\hline $\begin{array}{l}\text { ISAAC Phase } \\
3 \text { centers in } \\
\text { Africa } \\
\text { (Morroco } \\
\text { and } \\
\text { Nigeria) } \\
\text { Children }\end{array}$ & 2656 & 1 & $1.24[1.14-1.35]$ & - & $\begin{array}{l}\text { Brunekreef et al., } \\
\quad 2009 \text { [35]. }\end{array}$ \\
\hline
\end{tabular}


of a road have a high risk of developing asthma. This increase of risk of asthma follows a linear relationship with the proximity of residences to a road (adjusted odds ratio $=1.17$ per 30 m proximity, $95 \%$ CI 1.01 to 1.36 ) (Table 1 ). These results show that living near a road traffic is associated with an increasing risk of asthma and that other environmental factors are also likely to be significant. The analysis of "International Study of Asthma and Allergies in Childhood" (ISAAC) [35] study has also shown a dose-response relationship between road traffic close to residences and a difficult breathing, rhino-conjunctivitis and eczema in children in Nigeria and Morocco (Table 1). In Ibadan, it was also shown that most places where high particulate concentration was observed, impairment of pulmonary function could be noticed on residents [36].

Another study was carried out by the Mustapha et al., 2011 [37] on children from schools of low socio-economic areas in Nigeria who are exposed to multiple sources of both outdoor and indoor air pollution. This study showed that traffic related to air pollution in the proximity of residences was associated with respiratory symptoms such as wheeze, cough, phlegm and rhinitis.

In Ethiopia, a study on adults and children in an urban community [34] found among the 3592 individuals living in less than $150 \mathrm{~m}$ of a road that the risk of wheezing increased significantly in a linear relationship with the proximity of a road (adjusted OR $=1.17$ by $30 \mathrm{~m}$ proximity, $95 \%$ CI: $1.01-1.36$ ).

\subsubsection{Epidemiology of Air Pollution Related to Traffic and COPD in Africa}

It has been shown that air pollution is a risk factor for asthma and COPD. Air pollution can be a cause of exacerbation of COPD. However, the role of air pollution in the occurrence of COPD remains to be demonstrated [5]. In Africa, most prevalence studies of COPD have been conducted on specific groups of the population: miners, farmers or workers in industrial areas and also in hospital patients [38]-[43]. The prevalence of chronic bronchitis among no-exposed workers varied between $3.5 \%$ and $17 \%$ [39] [40] [41] and was always higher among exposed workers (4.1\% to 38.5\%) [38]-[43]. In Africa, the proportion of patients with COPD varies from country to country, from $2.7 \%$ in pneumology services in Conakry to $14 \%$ in specialized hospitals in pneumology in Morocco [27] [44] [45] [46] [47] [48]. In Tunisia, a study [49] was carried out to determine the prevalence of COPD on no-smokers adult population. A prevalence of $4.7 \%$ of COPD was found (Table 2). Other studies have also been done on the prevalence of COPD in adults, regardless of smoking status in different African countries, with respective prevalences of $11.8 \%$ in Malawi, $12.6 \%$ in Morocco, 16.2\% in Uganda and 4.9\% in Algeria [50] [51] [52] [53] (Table 2).

\section{Discussion}

In developing countries, particularly in Africa, where social mobility is important in cities, succeeding in controlling traffic as well as reducing air pollution related to traffic are desirable goals. However, it is more difficult to reach them in 
Table 2. Prevalence of COPD in some countries in Africa.

\begin{tabular}{cccc}
\hline Population & Number of subjects & $\begin{array}{c}\text { Prevalence of Chronic } \\
\text { Pulmonary Obstructive } \\
\text { Disease (COPD) (\%) }\end{array}$ & References \\
\hline $\begin{array}{c}\text { Tunisia } \\
\text { No smokers } \\
\text { Adults } \\
\text { Malawi } \\
\text { Adults }\end{array}$ & 485 & 4.7 & $\begin{array}{c}\text { Denguezli } \text { et al., 2016 } \\
\text { [49]. }\end{array}$ \\
$\begin{array}{c}\text { Morocco } \\
\text { Adults }\end{array}$ & 749 & 11.8 & Meghji et al., 2016 [53]. \\
$\begin{array}{c}\text { Uganda } \\
\text { Adults }\end{array}$ & 768 & 12.6 & El Rhazi et al., 2016 [52]. \\
$\begin{array}{c}\text { Algeria } \\
\text { Adults }\end{array}$ & 588 & 16.2 & Gemert et al., 2015 [51]. \\
\hline
\end{tabular}

the countries of the South than in the countries of the North. Socio-demographic constraints are also present in Africa: migration flows from the population to the cities must be controlled, as well as the extension of residential areas at the periphery of cities [9]. The World Bank, through its reports on air pollution, has suggested a number of strategies to reduce air pollution in developing countries [54]. The first strategy is to assess air pollution in cities by measuring the level of pollution with real-time measurement systems, then establishing fixed air quality monitoring sites. These air quality monitoring sites have been set up only in some African cities such as Dakar, Algiers and Casablanca. The second strategy is to assess the health effects of air pollution on the population through epidemiological studies. These epidemiological studies will allow us to know the prevalence of chronic respiratory diseases in the most polluted urban areas and also to make correlational studies between the levels of air pollution and the morbidity of chronic respiratory and cardiovascular diseases. A multidisciplinary approach to research is essential for an effective program to control air pollution. Specialists in medicine, natural sciences, meteorology, sociology, urbanization and law must be well integrated to fight this threat. In West Africa, an Ecohealth Chair has been created, bringing together four universities of four African capitals (Cotonou, Dakar, Ouagadougou and Abidjan). This chair includes multidisciplinary researchers working on the topic of air pollution and chronic respiratory diseases in West Africa. Information is another very important aspect of controlling air pollution. Public authorities must be sensitized about the problem of air pollution, especially from traffic, its importance and its toxic effects on health. In the sense, vigorous information and awareness campaigns should be set up to alert African populations about the respiratory effects of air pollution. These campaigns could bring populations to cooperate more easily in measures or controls taken by governments or health authorities to make the ambient air healthier. Citizens' education is also essential in order to make them understand that having a good air quality is in their interest for their health. Education 
should also include potential polluters (e.g. public transporters, drivers of used cars, etc.) to control their environment. After these scientific and educational strategies, the regulatory approach is inevitable in order to impose a minimum of laws in order to get a significant reduction of polluting emissions, particularly from cars, in big African cities. To limit these emissions, it is necessary to impose reasonable and applicable standards of air quality. For example, in Senegal, the Senegalese Standardization Agency (ASN) has set standards for concentrations of pollutants different from those of WHO that are more feasible and applicable to the local context of Dakar. Combustion of fuel from cars or engines causing air pollution and its effects on health could be controlled through the use of unleaded gasoline and improved crude oil refining techniques [17]. Effectiveness mechanism of control such as compulsory car inspections to eliminate big polluters and not well maintained cars should be more widely used. Traffic management reduces significantly the exposure of urban residents. Urban planning is an important lever to reduce air pollution due to traffic in cities. A better integration of environmental and health aspects in urban planning could improve the quality of ambient air in cities [55]. In Europe, WHO [54] has given some examples of actions to reduce air pollution linked to traffic through urban planning by the prevention of traffic congestion, the creation of green spaces, the separation of pedestrians and cyclists from traffic, an effective promotion focused on the services and clean public transportations to improve traffic fluidity. These measures could be applicable in African cities to improve the quality of the air we breathe (Figure 2).

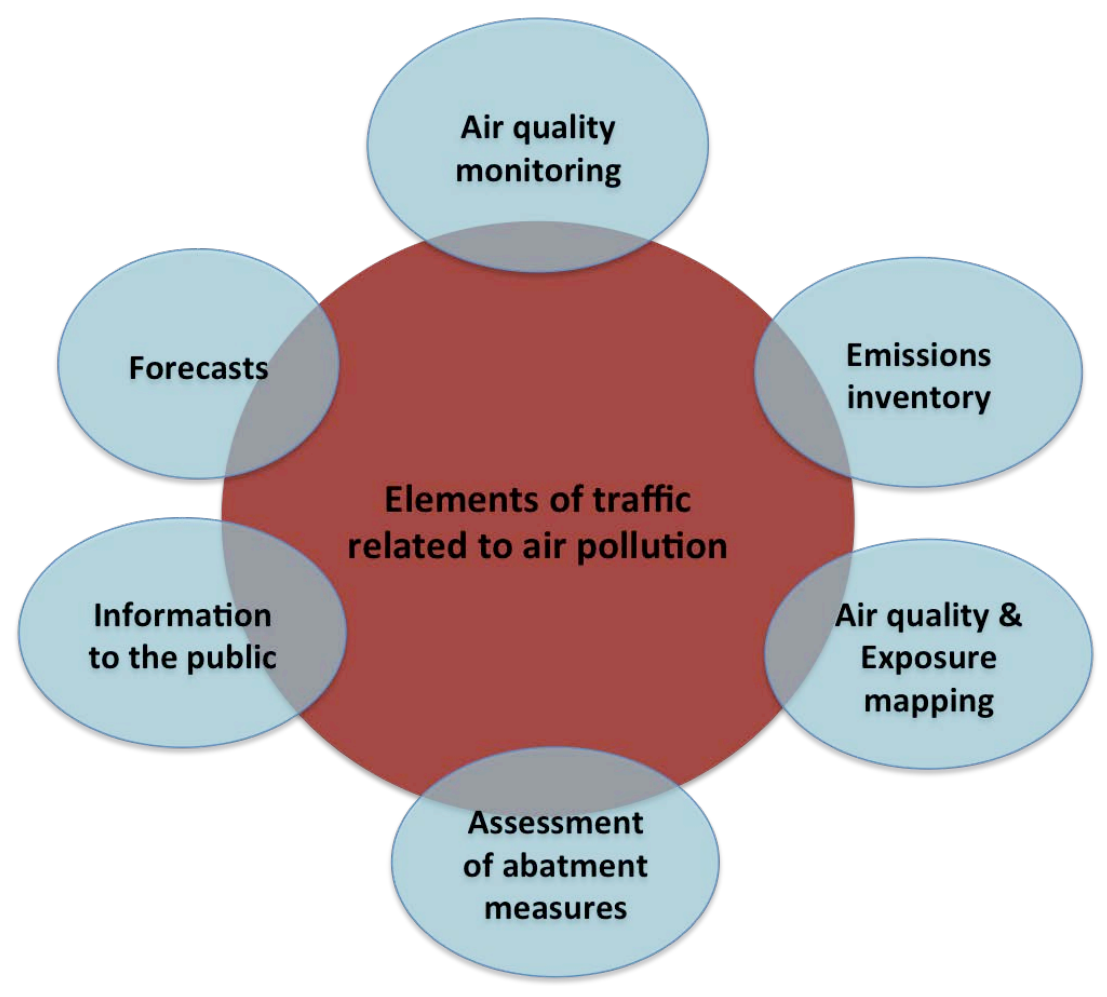

Figure 2. Strategies to reduce air pollution related to traffic in Africa. 


\section{Conclusion}

A high prevalence of chronic respiratory diseases was noted in the Africa region. As in the case of developing countries, Africa is facing more severe air pollution due to intense energy consumption, large scale demolishment and reconstructions, increased emissions from transportation, and biomass combustion compared to developed countries that have been industrialized for years. Air pollution from cars is associated with an increased risk of CRD in Africa. Little research has been done on the effects of air pollution from cars on respiratory health in contrast to indoor air pollution, in particular that related to the combustion of biomass. The same countries often do such research. There should be more African countries interested in the health effects of air pollution, especially as the burden of respiratory non communicable diseases is becoming more and more severe in Africa. It is therefore important to reduce the share of air pollution as a risk factor for CRD. Socio-economic, cultural, political and other environmental risk factors such as tobacco are also likely to have a key role in the occurrence and exacerbation of these CRD, and must be evaluated more thoroughly to enable effective action.

\section{Acknowledgements}

We thank the International Development Research Centre (IRDC) for the financial support to this work.

\section{Conflict of Interest}

The authors declare that they have no conflicts of interest in relation to this article.

\section{References}

[1] World Health Organization (2014) Ambient (Outdoor) Air Quality and Health. World Health Organization, Geneva, Switzerland.

[2] OECD Development Centre Working Papers. (2016) The cost of air pollution in Africa.

[3] Phalen, R. (2008) Inhalation Studies: Foundations and Techniques. Informa Health Care, New York.

[4] Spiric, V., et al. (2012) The Impact of Air Pollution on Chronic Respiratory Diseases. Pollution Journal Environnemental Studies, 21, 481-490.

[5] Kurt, O.K., J. Zhang, and K.E. Pinkerton. (2016) Pulmonary Health Effects of Air Pollution. Current Opinion in Pulmonary Medicine, 22, 138-143. https://doi.org/10.1097/MCP.0000000000000248

[6] Murray, C.J., et al. (2012) Disability-Adjusted Life Years (DALYS) for 291 Diseases and Injuries in 21 Regions, 1990-2010: A Systematic Analysis for the Global Burden of Disease Study 2010. Lancet, 380, 2197-2223. https://doi.org/10.1016/S0140-6736(12)61689-4

[7] Finney, L.J., et al. (2013) Chronic Obstructive Pulmonary Disease in Sub-Saharan Africa: A Systematic Review. The International Journal of Tuberculosis and Lung Disease, 17, 583-589. https://doi.org/10.5588/ijtld.12.0619 
[8] United Nations Population Division (2010) World Urbanization Prospects: The 2009 Revision Data Highlights. United Nations.

[9] Nejjari, C., et al. (2003) Air Pollution: A New Respiratory Risk for Cities in Low-Income Countries. The International Journal of Tuberculosis and Lung Disease, 7, 223-231.

[10] UNEP (United Nations Environment Programme) (2011) Urban Air Pollution.

[11] Cacciola, R.R., Sarva, M. and Polosa, R. (2002) Adverse Respiratory Effects and Allergic Susceptibility in Relation to Particulate Air Pollution: Flirting with Disaster. Allergy, 57, 281-286. https://doi.org/10.1034/j.1398-9995.2002.1r3315.x

[12] World Health Organization (2005) Health Effects of Transport-Related Air Pollution. WHO Regional Office for Europe, Copenhagen, 125-165.

[13] Health Effects Institute (2009) Traffic-Related Air Pollution: A Critical Review of the Literature on Emissions, Exposure, and Health Effects.

[14] Han, X. and Naeher, L.P. (2006) A Review of Traffic-Related Air Pollution Exposure Assessment Studies in the Developing World. Environment International, 32, 106-120.

[15] Migliore, E., et al. (2009) Respiratory Symptoms in Children Living near Busy Roads and Their Relationship to Vehicular Traffic: Results of an Italian Multicenter Study (SIDRIA 2). Environmental Health, 8, 27. https://doi.org/10.1186/1476-069X-8-27

[16] Linden, J., et al. (2012) Intra-Urban Air Pollution in a Rapidly Growing Sahelian City. Environment International, 40, 51-62.

[17] Wu, W.T., et al. (2011) Health Impacts Associated with the Implementation of a National Petrol-Lead Phase-Out Program (PLPOP): Evidence from Taiwan between 1981 and 2007. Science of the Total Environment, 409, 863-867.

[18] Chen, M.L. and Mao, I.F. (1998) Spatial Variations of Airborne Particles in Metropolitan Taipei. Science of the Total Environment, 209, 225-231.

[19] Naeher, L.P., et al. (1999) Healthy Women's PEF Variations with Ambient Summer Concentrations of PM10, PM2.5, SO42-, H+, and O3. American Journal of Respiratory and Critical Care Medicine, 160, 117-125. https://doi.org/10.1164/ajrccm.160.1.9808153

[20] Shendell, D.G. and Naeher, L.P. (2002) A Pilot Study to Assess Ground-Level Ambient Air Concentrations of Fine Particles and Carbon Monoxide in Urban Guatemala. Environment International, 28, 375-382.

[21] Crouse, D.L., et al. (2010) Postmenopausal Breast Cancer Is Associated with Exposure to Traffic-Related Air Pollution in Montreal, Canada: A Case-Control Study. Environmental Health Perspectives, 118, 1578-1583. https://doi.org/10.1289/ehp.1002221

[22] Lamsal, L.N., et al. (2013) Scaling Relationship for $\mathrm{NO}_{2}$ Pollution and Urban Population Size: A Satellite Perspective. Environmental Science \& Technology, 47, 7855-7861. https://doi.org/10.1021/es400744g

[23] Eliasson, I., Jonsson, P. and Holmer, B. (2009) Diurnal and Intra-Urban Particle Concentrations in Relation to Windspeed and Stability during the Dry Season in Three African Cities. Environmental Monitoring and Assessment, 154, 309-324. https://doi.org/10.1007/s10661-008-0399-y

[24] Dionisio, K.L., et al. (2010) Air Pollution in Accra Neighborhoods: Spatial, Socioeconomic, and Temporal Patterns. Environmental Science \& Technology, 44, 2270-2276. https://doi.org/10.1021/es903276s 
[25] Kinney, P.L., et al. (2011) Traffic Impacts on PM (2.5) Air Quality in Nairobi, Kenya. Environmental Science \& Policy, 14, 369-378.

[26] Jiang, X.Q., Mei, X.D. and Feng, D. (2016) Air Pollution and Chronic Airway Diseases: What Should People Know and Do? Journal of Thoracic Disease, 8, E31-E40.

[27] Pope, C.A. and Dockery, D.W. (2006) Health Effects of Fine Particulate Air Pollution: Lines That Connect. Journal of the Air \& Waste Management Association, 56, 709-742. https://doi.org/10.1080/10473289.2006.10464485

[28] Rokaw, S.N., et al. (1980) The UCLA Population Studies of Chronic Obstructive Respiratory Disease. 3. Comparison of Pulmonary Function in Three Communities Exposed to Photochemical Oxidants, Multiple Primary Pollutants, or Minimal Pollutants. Chest, 78, 252-262. https://doi.org/10.1378/chest.78.2.252

[29] Pope, C.A., Bates, D.V. and Raizenne, M.E. (1995) Health Effects of Particulate Air Pollution: Time for Reassessment? Environmental Health Perspectives, 103, 472-480. https://doi.org/10.1289/ehp.95103472

[30] Kunzli, N., et al. (2000) Public-Health Impact of Outdoor and Traffic-Related Air Pollution: A European Assessment. The Lancet, 356, 795-801.

[31] Norman, R., et al. (2007) Estimating the Burden of Disease Attributable to Urban Outdoor Air Pollution in South Africa in 2000. South African Medical Journal, 97, 782-790.

[32] Naidoo, R.N., et al. (2013) Ambient Pollution and Respiratory Outcomes among Schoolchildren in Durban, South Africa. SAJCH, 7, 127-134.

https://doi.org/10.7196/sajch.598

[33] Shirinde, J., Wichmann, J. and Voyi, K. (2015) Allergic Rhinitis, Rhinoconjunctivitis and Hayfever Symptoms among Children Are Associated with Frequency of Truck Traffic near Residences: A Cross Sectional Study. Environmental Health, 14, 84. https://doi.org/10.1186/s12940-015-0072-1

[34] Venn, A., et al. (2005) Proximity of the Home to Roads and the Risk of Wheeze in an Ethiopian Population. Occupational and Environmental Medicine, 62, 376-380. https://doi.org/10.1136/oem.2004.017228

[35] Brunekreef, B., et al. (2009) Self-Reported Truck Traffic on the Street of Residence and Symptoms of Asthma and Allergic Disease: A Global Relationship in ISAAC Phase 3. Environmental Health Perspectives, 117, 1791-1798. https://doi.org/10.1289/ehp.0800467

[36] Ana, G.R., et al. (2009) Identification and Initial Characterization of Prominent Air Pollution Sources and Respiratory Health at Secondary Schools in Ibadan, Nigeria. Journal of Asthma, 46, 670-676. https://doi.org/10.1080/02770900902972152

[37] Mustapha, B.A., et al. (2011) Traffic Air Pollution and Other Risk Factors for Respiratory Illness in Schoolchildren in the Niger-Delta Region of Nigeria. Environmental Health Perspectives, 119, 1478-1482. https://doi.org/10.1289/ehp.1003099

[38] Mustafa, K.Y., et al. (1978) Byssinosis, Respiratory Symptoms and Spirometric Lung Function Tests in Tanzanian Sisal Workers. British Journal of Industrial Medicine, 35, 123-128. https://doi.org/10.1136/oem.35.2.123

[39] Yach, D., et al. (1985) A Respiratory Epidemiologic Survey of Grain Mill Workers in Cape Town, South Africa. The American Review of Respiratory Disease, 131, 505-510.

[40] Ballal, S.G. (1986) Respiratory Symptoms and Occupational Bronchitis in Chromite Ore Miners, Sudan. The Journal of Tropical Medicine and Hygiene, 89, 223-228.

[41] Myers, J.E., et al. (1987) A Respiratory Epidemiological Survey of Workers in a 
Small South African Foundry. American Journal of Industrial Medicine, 12, 1-9. https://doi.org/10.1002/ajim.4700120102

[42] Laraqui, C.H., et al. (2001) Prevalence of Respiratory Problems in Workers at Two Manufacturing Centers of Ready-Made Concrete in Morocco. International Journal of Tuberculosis and Lung Disease, 5, 1051-1058.

[43] Laraqui, C.H., et al. (2003) The Prevalence of Respiratory Symptomes and Immediate Hypersensitivity Reactions in a Population Exposed to Flour and Cereal Dust in Five Flour Mills in Morocco. International Journal of Tuberculosis and Lung Disease, 7, 382-389.

[44] Moller, W., et al. (2008) Deposition, Retention, and Translocation of Ultrafine Particles from the Central Airways and Lung Periphery. American Journal of Respiratory and Critical Care Medicine, 177, 426-432. https://doi.org/10.1164/rccm.200602-3010C

[45] Pujades-Rodriguez, M., et al. (2009) Effect of Traffic Pollution on Respiratory and Allergic Disease in Adults: Cross-Sectional and Longitudinal Analyses. BMC Pulmonary Medicine, 9, 42. https://doi.org/10.1186/1471-2466-9-42

[46] Schikowski, T., et al. (2010) Decline in Air Pollution and Change in Prevalence in Respiratory Symptoms and Chronic Obstructive Pulmonary Disease in Elderly Women. Respiratory Research, 11, 113. https://doi.org/10.1186/1465-9921-11-113

[47] Andersen, Z.J., et al. (2011) Chronic Obstructive Pulmonary Disease and Long-Term Exposure to Traffic-Related Air Pollution: A Cohort Study. American Journal of Respiratory and Critical Care Medicine, 183, 455-461. https://doi.org/10.1164/rccm.201006-0937OC

[48] Nuvolone, D., et al. (2011) Geographical Information System and Environmental Epidemiology: A Cross-Sectional Spatial Analysis of the Effects of Traffic-Related Air Pollution on Population Respiratory Health. Environmental Health, 10, 12. https://doi.org/10.1186/1476-069X-10-12

[49] Denguezli, M., et al. (2016) COPD in Nonsmokers: Reports from the Tunisian Population-Based Burden of Obstructive Lung Disease Study. PLOS ONE, 11, e0151981. https://doi.org/10.1371/journal.pone.0151981

[50] Khelafi, R., et al. (2011) Epidemiology of Chronic Obstructive Pulmonary Disease in Algiers. Revue des Maladies Respiratoires, 28, 32-40.

[51] Van Gemert, F., et al. (2015) Prevalence of Chronic Obstructive Pulmonary Disease and Associated Risk Factors in Uganda (FRESH AIR Uganda): A Prospective Cross-Sectional Observational Study. The Lancet Global Health, 3, e44-e51.

[52] El Rhazi, K., et al. (2016) Prevalence of Chronic Obstructive Pulmonary Disease in Fez, Morocco: Results from the BOLD Study. International Journal of Tuberculosis and Lung Disease, 20, 136-141. https://doi.org/10.5588/ijtld.15.0029

[53] Meghii, J., et al. (2016) Noncommunicable Lung Disease in Sub-Saharan Africa. A Community-Based Cross-Sectional Study of Adults in Urban Malawi. American Journal of Respiratory and Critical Care Medicine, 194, 67-76. https://doi.org/10.1164/rccm.201509-1807OC

[54] Krzyzanowski, M. (2005) Healths Effects of Transport-Related Air Pollution: Summary for Policy Makers. OMS Europe.

[55] Brugge, D., et al. (2015) Developing Community-Level Policy and Practice to Reduce Traffic-Related Air Pollution Exposure. Environmental Justice, 8, 95-104. https://doi.org/10.1089/env.2015.0007 
Submit or recommend next manuscript to SCIRP and we will provide best service for you:

Accepting pre-submission inquiries through Email, Facebook, LinkedIn, Twitter, etc. A wide selection of journals (inclusive of 9 subjects, more than 200 journals)

Providing 24-hour high-quality service

User-friendly online submission system

Fair and swift peer-review system

Efficient typesetting and proofreading procedure

Display of the result of downloads and visits, as well as the number of cited articles Maximum dissemination of your research work

Submit your manuscript at: http://papersubmission.scirp.org/

Or contact health@scirp.org 